www.nature.com/pj

\title{
A novel polyphenol: synthesis, characterization and investigation of its thermal and electrochemical properties
}

\author{
Hacı Ökkeş Demir
}

The chemical synthesis of a new type of polyphenol was achieved by oxidative polycondensation of 4-((2-phenylhydrazono)methyl) phenol (4-PHMP). The polymerization of 4-PHMP was performed using sodium hypochlorite and air $\left(\mathrm{O}_{2}\right)$ as oxidizing agents in an aqueous alkaline medium under various polymerization conditions. The molecular weight of the polymer was determined by gel permeation chromatography, and the polymeric structure was characterized by elemental analysis, ultraviolet-visible, Fourier transform infrared and nuclear magnetic resonance techniques. In addition, thermal and electrochemical properties of the synthesized compounds were investigated. According to electrochemical measurements, the polymer had a low band gap $\left(E_{g}^{\prime}=1.52 \mathrm{eV}\right)$ and appeared to be an interesting candidate for solar-cell applications.

Polymer Journal (2012) 44, 699-705; doi:10.1038/pj.2012.17; published online 14 March 2012

Keywords: conjugated polymer; low band gap; oxidative polycondensation; polymer Schiff bases; thermal analysis

\section{INTRODUCTION}

Polymers with highly conjugated chains have drawn considerable attention in the last few years because they are promising candidates for a wide variety of applications, such as electronics, optoelectronics and photonics. ${ }^{1-3}$ One class of these polymers is polyphenols, which contain active hydroxyl $(-\mathrm{OH})$ groups that are synthesized by enzymatic polymerization ${ }^{4,5}$ or oxidative polycondensation methods. ${ }^{6,7}$ Oxidative polycondensation is advantageous in that this process can offer simple and mild reaction conditions when compared with other methods. Many researchers have been trying to improve the properties of polyphenols by adding functional groups to their structures. It is well known that Schiff bases can be easily synthesized and have conjugated structures. If the aromatic-imine group is attached to the benzene rings of polyphenols, the conjugation lengths can be increased. Kaya et al. ${ }^{8}$ synthesized oligo-2-ptolylazomethinephenol with phenylazo pendent groups for the first time. Thus far, the detailed polymerization behaviors of the oxidative polycondensation of NO-type phenoxy imines have been widely investigated by Kaya et al. and others. ${ }^{9-11}$ However, the polymerization of NNO-type phenoxy-ketimine or phenoxy-imine monomers has not yet been studied. Previously, we focused on the formation of NNO-type poly(phenoxy-ketimine). ${ }^{12}$ On the basis of these studies, we decided to proceed to the construction of NNO-type poly(phenoxy-imine).

In this paper, we report our findings on the oxidative polycondensation of a new type of phenoxy-imine monomer. We evaluated the thermal and electrochemical properties of the newly synthesized compounds and compared the results with those from previous studies.

\section{EXPERIMENTAL PROCEDURES}

Materials

Several chemicals, including $p$-hydroxybenzaldehyde, phenylhydrazine, sodium hypochlorite $(11 \%)$, hydrogen peroxide $(30 \%)$, hydrochloric acid $(37 \%)$, sulfuric acid (98\%), potassium hydroxide, silver nitrate, diethyl ether, dichloromethane, ethanol, ethyl acetate, acetone, dimethylformamide, dimethyl sulfoxide (DMSO), tetrahydrofuran, methanol, chloroform and $n$-hexane, were purchased from Merck Schuchardt OHG (Hohenbrunn, Germany). All of these chemicals were used without further purification.

Instrumentation and characterization techniques

Elemental analysis was carried out with a LECO CHNS-932 (LECO Corporation, St Joseph, MI, USA). The infrared and ultraviolet-visible (UV-vis) spectra were measured using a Perkin-Elmer Fourier transform infrared (FTIR) Spectrum one (Perkin-Elmer, Llantrisant, UK) and Perkin-Elmer Lambda 25 (Perkin-Elmer, Shelton, CT, USA), respectively. The FTIR spectra were recorded using universal attenuated total reflectance sampling accessories (4000-650 $\mathrm{cm}^{-1}$ ) Pike GladiATR (Madison, WI, USA). ${ }^{1} \mathrm{H}$-nuclear magnetic resonance (NMR) spectra (Varian XL-400 NMR, Varian, Palo Alto, CA, USA) was also recorded at $25^{\circ} \mathrm{C}$ in DMSO with tetramethylsilane as an internal standard. Thermal data were obtained with a Perkin-Elmer Diamond Thermal Analyzer. The thermo gravimetry-differential thermal analysis measurements were obtained between 20 and $1000^{\circ} \mathrm{C}$ (under $\mathrm{N}_{2}$; flow rate, $10^{\circ} \mathrm{C} \mathrm{min}{ }^{-1}$ ). The number average molecular weight, weight average molecular weight and polydispersity index were determined by size exclusion chromatography 
(Shimadzu Co., Kyoto, Japan). The following conditions were used for chromatography: SGX ( $100 \mathrm{~A}^{\circ}$ and $7 \mathrm{~nm}$ diameter loading material) $3.3 \mathrm{~mm}$ i.d. $\times 300 \mathrm{~mm}$ column; eluent: dimethylformamide $\left(0.4 \mathrm{ml} \mathrm{min}^{-1}\right)$, polystyrene standards. A refractive index detector was used to analyze the product at $25^{\circ} \mathrm{C}$. The optical band gaps $\left(E_{g}\right)$ of the synthesized compounds were calculated from their absorption edges obtained by UV-vis measurements. Cyclic voltammetry measurements were carried out using a CHI $660 \mathrm{C}$ Electrochemical Analyzer ( $\mathrm{CH}$ Instruments, Austin, TX, USA) at a potential scan rate of $20 \mathrm{mV} \mathrm{s}^{-1}$. The electrochemical cell consists of an Ag wire as the reference electrode, a $\mathrm{Pt}$ wire as the counter electrode and glassy carbon electrode as the working electrode immersed in $\operatorname{TBAPF}_{6}(0.1 \mathrm{M})$ as the supporting electrolyte. The voltammetric measurements were carried out in acetonitrile for the monomer and acetonitrile/DMSO mixture (v/v, 2:1) for the polymer. An ultrasonic bath was used to dissolve the samples. The highest occupied molecular orbital-lowest unoccupied molecular orbital energy levels and electrochemical band gaps $\left(E_{g}{ }^{\prime}\right)$ were calculated from the oxidation and reduction onset values.

\section{Synthesis}

Preparation of 4-((2-phenylhydrazono)methyl)phenol (4-PHMP). The monomer was prepared by a standard condensation method. ${ }^{13}$ Solutions of phenyl hydrazine $(1.0814 \mathrm{~g}, 10 \mathrm{mmol})$ in ethanol $(2 \mathrm{ml})$ and $p$-hydroxybenzaldehyde $(1.2212 \mathrm{~g}, 10 \mathrm{mmol})$ in ethanol $(3 \mathrm{ml})$ were mixed and stirred for $\sim 30 \mathrm{~min}$ at room temperature. The precipitated product was filtered and washed with cold ethanol. The monomer (as shown in Scheme 1) was purified by recrystallization in ethanol to provide $2.06 \mathrm{~g}$ of the compound as a pale yellow-white solid. The purity was confirmed by the silica plates and melting point determination.

4-PHMP: yield: $97 \% ; R_{\mathrm{f}}: 0.27\left(\mathrm{SiO}_{2}\right.$, hexane/ethyl acetate, v/v, 3:1); melting point: $183{ }^{\circ} \mathrm{C} ;{ }^{1} \mathrm{H}-\mathrm{NMR}\left(400 \mathrm{MHz}, \mathrm{DMSO}-d_{6}\right): \delta$ p.p.m. $=10.01(1 \mathrm{H}, \mathrm{s}$, $\mathrm{C} \underline{H}=\mathrm{N}), 9.60(1 \mathrm{H}, \mathrm{s} \mathrm{O} \underline{H}), 7.77(1 \mathrm{H}, \mathrm{s}, \mathrm{N} \underline{H}), 7.46(2 \mathrm{H}, \mathrm{d}, J=8.6 \mathrm{~Hz}, \mathrm{Ar} \underline{H})$, $7 . \overline{17}(2 \mathrm{H}, \mathrm{t}, J=8.2 \mathrm{~Hz}, \overline{\mathrm{Ar}} H), 7.01(2 \mathrm{H}, \overline{\mathrm{d}}, J=8.2 \mathrm{~Hz}, \operatorname{Ar} H), 6.78(2 \mathrm{H}, \overline{\mathrm{d}}$, $J=8.6 \mathrm{~Hz}, \operatorname{Ar} \underline{H}), 6.68(1 \mathrm{H}, \mathrm{t}, J=7.3 \mathrm{~Hz}, \operatorname{Ar} \underline{H}) ;$ FTIR $v=3399(\mathrm{O}-\mathrm{H}), 3290$ $(\mathrm{N}-\mathrm{H}), 3033$ (C-H aryl), $2970-2860$ (C- $-\mathrm{H}$ aliphatic), $1596(\mathrm{HC}=\mathrm{N})$, $1505-1437(\mathrm{C}=\mathrm{C}), 1251(\mathrm{C}-\mathrm{N}), 1167(\mathrm{C}-\mathrm{O}), 1098(\mathrm{~N}-\mathrm{N}) \mathrm{cm}^{-1}$; UV-vis $\lambda_{\max }=217,243,305$ and $345 \mathrm{~nm}$; analytical calculated for $\mathrm{C}_{13} \mathrm{H}_{12} \mathrm{~N}_{2} \mathrm{O}$ : C,73.56; H, 5.70 and N, 13.20. Found: C, 72.74; H, 5.65 and N, 13.24.

The oxidative polycondensation of 4-PHMP using NaOCl. The compound 4-PHMP $(0.53 \mathrm{~g}, 2.5 \mathrm{mmol})$ was dissolved in an aqueous solution of $\mathrm{KOH}$ $(0.14 \mathrm{~g}, 2.5 \mathrm{mmol}, 10 \%)$ and placed into a $25-\mathrm{ml}$ three-necked round-bottomed flask that was fitted with a condenser, a thermometer and a stirrer, in addition to a funnel containing $\mathrm{NaOCl}$. After heating to the appropriate temperature, $\mathrm{NaOCl}$ was added dropwise over $\sim 30 \mathrm{~min}$. The reaction mixture was stirred under different conditions (Figures 1-4). The mixture was neutralized with $\mathrm{HCl}$ $(1.0 \mathrm{M}, 0.5 \mathrm{ml})$ at room temperature. The mixture was filtered and washed with hot water $(25 \mathrm{ml}$, three times), and the removal of mineral salts was confirmed using an $\mathrm{AgNO}_{3}$ solution. Then, unreacted 4-PHMP was separated from the reaction products by washing with a diethyl ether/hexane mixture $(10 \mathrm{ml}, \mathrm{v} / \mathrm{v}$, $1: 1)$ and dried in an oven at $105^{\circ} \mathrm{C}$ (Scheme 1).

Poly(4-PHMP): yield: $66 \% ; R_{\mathrm{f}}: 0\left(\mathrm{SiO}_{2}\right.$, hexane/ethyl acetate, $\left.\mathrm{v} / \mathrm{v}, 3: 1\right)$ and $R_{\mathrm{f}}: 0.31\left(\mathrm{SiO}_{2}\right.$, methanol); melting point: $>250{ }^{\circ} \mathrm{C}$ decomposed. ${ }^{1} \mathrm{H}-\mathrm{NMR}$ $\left(400 \mathrm{MHz}, \quad\right.$ DMSO- $\left.d_{6}\right): \delta$ p.p.m. $=10.18 \quad(\mathrm{~s}, \mathrm{CH}=\mathrm{N}), 9.93$ (bs, $\left.\mathrm{OH}\right)$, $7.97-6.35(\mathrm{~m}, \mathrm{~N} \underline{H}$ and $\operatorname{Ar} \underline{H})$. FTIR $v=3304(\overline{\mathrm{O}}-\mathrm{H}), 3183(\mathrm{~N}-\mathrm{H}), 3 \overline{063}$ (C-H aryl), 2959-2890 (C-H aliphatic), $1677(\mathrm{C}=\mathrm{O}), 1595(\mathrm{HC}=\mathrm{N})$, $1493-1454(\mathrm{C}=\mathrm{C}), 1275(\mathrm{C}-\mathrm{N}), 1234(\mathrm{C}-\mathrm{O}-\mathrm{C}), 1167(\mathrm{C}-\mathrm{O}), 1081(\mathrm{~N}-\mathrm{N})$ $\mathrm{cm}^{-1}$; UV-vis $\lambda_{\max }=227$ (shoulder), 280 and 345 (shoulder) nm; Anal. calculated for $\mathrm{C}_{13} \mathrm{H}_{10} \mathrm{~N}_{2} \mathrm{O}$ : C,74.26; H, 4.80 and N, 13.33. Found: C, 74.66; H, 4.74 and $\mathrm{N}, 13.26$.

The oxidative polycondensation of 4-PHMP using air $\left(\mathrm{O}_{2}\right)$. The compound 4-PHMP $(0.53 \mathrm{~g}, 2.5 \mathrm{mmol})$ was dissolved in an aqueous solution of $\mathrm{KOH}$ $(0.14 \mathrm{~g}, 2.5 \mathrm{mmol}, 10 \%)$ and placed into a $25-\mathrm{ml}$ three-necked round-bottomed flask that was fitted with a condenser, a thermometer and a stirrer, in addition to a glass tubing condenser for bringing in air. To prevent water loss in the reaction mixture and to neutralize the $\mathrm{CO}_{2}$ in the air to $\mathrm{KOH}, \mathrm{O}_{2}$ was passed through $200 \mathrm{ml}$ of an aqueous solution of $\mathrm{KOH}(20 \%)$ before passing through the reaction mixture. After heating to the appropriate temperature, $\mathrm{O}_{2}$ was bubbled through the reaction mixture at a rate ranging from 0.25 to $11 \mathrm{~h}^{-1}$ (Figures 1-4). At the end of the reaction, the mixture was cooled to room temperature and neutralized with $\mathrm{HCl}(1.0 \mathrm{M}, 0.5 \mathrm{ml})$, and the solid product was filtered and washed with hot water $(25 \mathrm{ml}$, three times). The removal of mineral salts was confirmed using $\mathrm{AgNO}_{3}$. Then, unreacted 4-PHMP was separated from the reaction products by washing with diethyl ether/hexane mixture $(10 \mathrm{ml}, \mathrm{v} / \mathrm{v}, 1: 1)$ and dried in an oven at $105^{\circ} \mathrm{C}$ (Scheme 1).

\section{RESULTS AND DISCUSSION}

\section{The investigation of synthesis conditions of 4-PHMP}

The oxidative polycondensation of 4-PHMP was investigated in different media. No polycondensation reaction was observed in a medium that was both acidic and organic using an oxidant such as

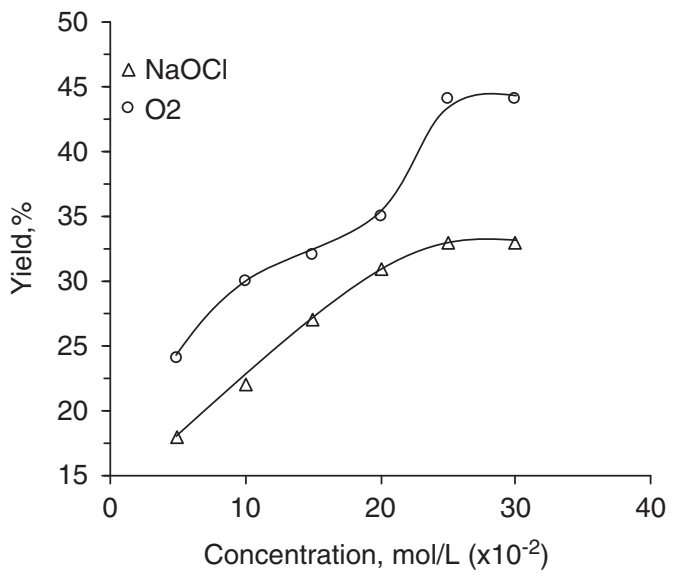

Figure 1 Effect of $\mathrm{KOH}$ concentration on the yield of polymer \{temperature: $50^{\circ} \mathrm{C}$, time: $5 \mathrm{~h}$, flow rate of $\mathrm{O}_{2}=0.75 \mathrm{Ih}^{-1}$ and $\left[4-\mathrm{PHMP}_{0}=\right.$ $\left.[\mathrm{NaOCl}]_{0}=0.25 \mathrm{moll}^{-1}\right\}$.

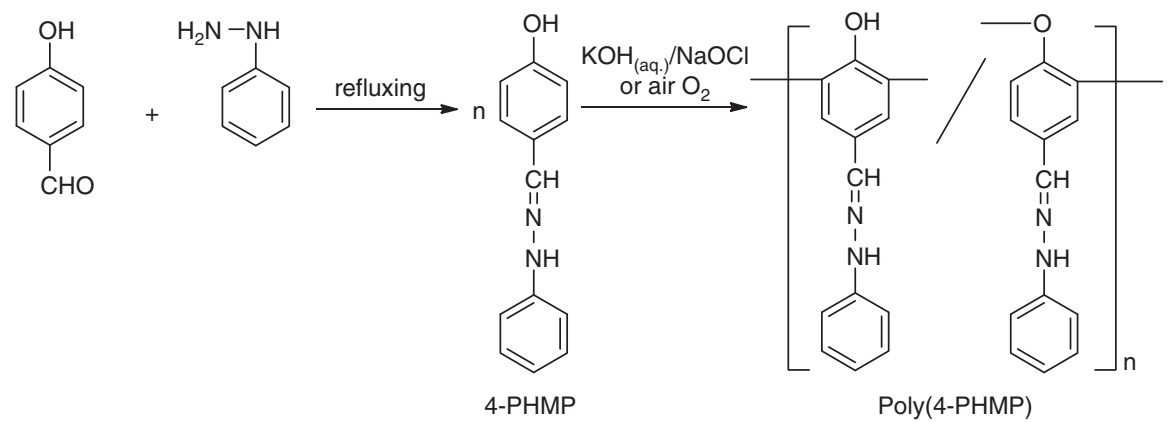

Scheme 1 The synthesis route for 4-PHMP and poly(4-PHMP). 


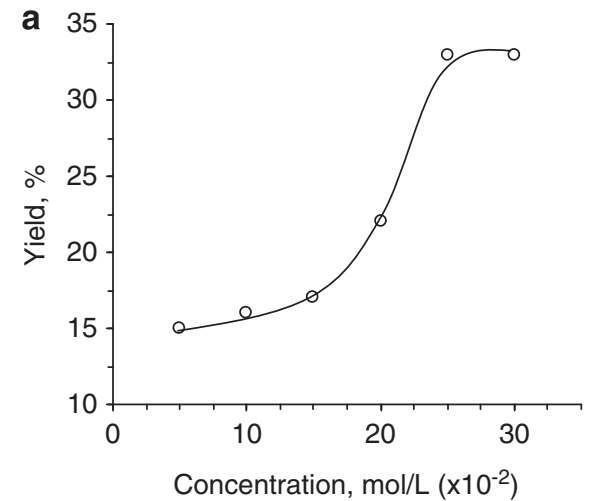

Figure 2 Effect of $\mathrm{NaOCl}$ concentration (a) and flow rate of $\mathrm{O}_{2}$ $\left[4-\mathrm{PHMP}_{0}=[\mathrm{KOH}]_{0}=0.25 \mathrm{moll}^{-1}\right\}$.

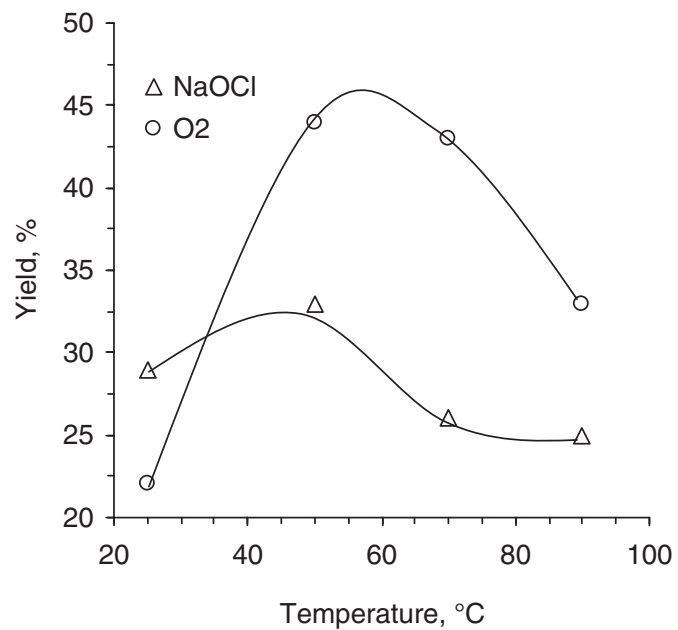

Figure 3 Effect of reaction temperature on the yield of polymer \{time: $5 \mathrm{~h}, \quad[4-\mathrm{PHMP}]_{0}=[\mathrm{NaOCl}]_{0}=[\mathrm{KOH}]_{0}=0.25 \mathrm{moll}^{-1}$, and flow rate of $\left.\mathrm{O}_{2}=1 \mathrm{Ih}^{-1}\right\}$.

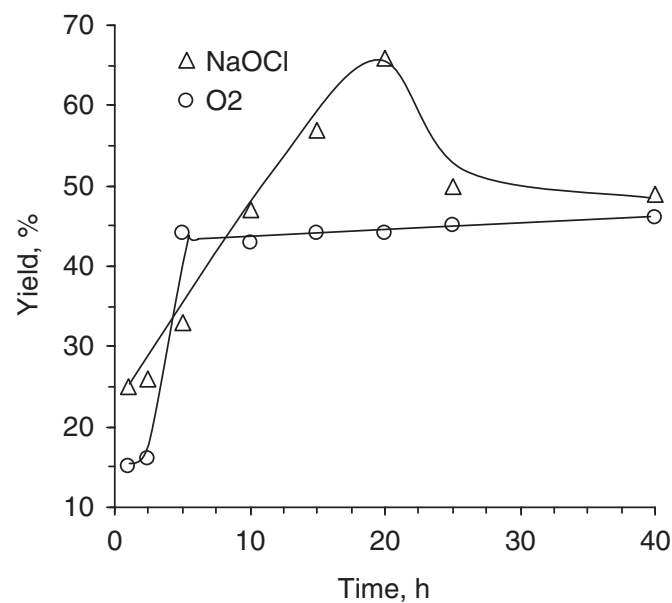

Figure 4 Effect of reaction time on the yield of polymer \{temperature: $50^{\circ} \mathrm{C}, \quad[4-\mathrm{PHMP}]_{0}=[\mathrm{NaOCl}]_{0}=[\mathrm{KOH}]_{0}=0.25 \mathrm{moll}^{-1}$, and flow rate of $\left.\mathrm{O}_{2}=1 \mathrm{Ih}^{-1}\right\}$.

$\mathrm{NaOCl}$ or $\mathrm{O}_{2}$. Although 4-PHMP showed oxidization in the aqueous alkaline medium using $\mathrm{O}_{2}$ and $\mathrm{NaOCl}$, it did not oxidize at the same conditions using $\mathrm{H}_{2} \mathrm{O}_{2}$ as an oxidant. After obtaining these results, the

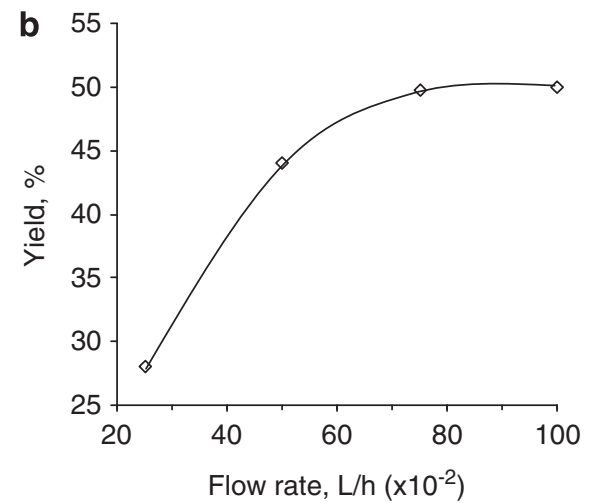

(b) on the yield of polymer \{temperature: $50^{\circ} \mathrm{C}$, time: $5 \mathrm{~h}$ and effect of various parameters, such as the initial concentrations of $\mathrm{KOH}$ and $\mathrm{NaOCl}$, the flow rates of $\mathrm{O}_{2}$, and reaction time and temperature, on the yield of oxidative polycondensation products were examined; the results are summarized in Figures 1-4. The yield of oxidative polycondensation products from 4-PHMP was 66\% under the optimum reaction conditions: $[4-\mathrm{PHMP}]_{0}=[\mathrm{KOH}]_{0}=[\mathrm{NaOCl}]_{0}=$ $0.25 \mathrm{moll}^{-1}$ at $50{ }^{\circ} \mathrm{C}$ for $20 \mathrm{~h}$.

As shown in Figures 1-4, the yield of each of these reactions was dependent on the temperature, time and initial concentrations of the oxidants. Although a high yield was obtained in experiments carried out with $\mathrm{O}_{2}$ as seen in Figures 1-3, the highest yield was obtained with the use of $\mathrm{NaOCl}$, which can be seen in Figure 4 and in Table 1.

\section{Solubility}

The solubility tests were performed with $1 \mathrm{mg}$ of monomer sample and $1 \mathrm{ml}$ solvent at $25^{\circ} \mathrm{C}$. The compounds 4-PHMP and poly $(4-$ PHMP) were stable at room temperature. Both compounds were soluble in highly polar solvents, such as methanol, DMSO, dimethylformamide, and solutions of $\mathrm{KOH}$ and concentrated $\mathrm{H}_{2} \mathrm{SO}_{4}$. The synthesized monomer was completely soluble in diethyl ether, $\mathrm{CHCl}_{3}$ and tetrahydrofuran, whereas its polymer was insoluble in these solvents.

In addition, a sensitive and selective thin-layer chromatographic method was used for the analysis of poly(4-PHMP). A comparison of 4-PHMP and its polymer was performed on silica plates. If a hexane/ ethyl acetate mixture $(\mathrm{v} / \mathrm{v}, 3: 1)$ was used as the solvent system, only monomer remained, possessing an $R_{\mathrm{f}}$ value of 0.27 . When only methanol was used as the solvent system, the $R_{\mathrm{f}}$ value of the polymer was measured as 0.31 .

\section{Structures of 4-PHMP and poly(4-PHMP)}

The electronic absorption spectral data for 4-PHMP and poly (4-PHMP) were obtained in methanol at room temperature and reported in the Experimental procedures. Figure 5 shows the UV-vis absorption spectra of 4-PHMP and poly(4-PHMP). The UV-vis spectra of 4-PHMP and poly(4-PHMP) were similar. The K bands, assigned to the $-\mathrm{OH}$ and the azomethine groups of 4-PHMP, were observed at 217 and $305 \mathrm{~nm}$, respectively. The B and R bands of 4-PHMP were observed at 243 and $345 \mathrm{~nm}$. The $\mathrm{K}, \mathrm{B}$ and R bands of poly(4-PHMP) were observed at 228 (shoulder), 280 and 344 (shoulder) nm, respectively. In addition, band shifting until $650 \mathrm{~nm}$ was observed in the poly(4-PHMP) spectrum, which was attributed to an increase in conjugation due to coupling between aromatic rings. 
Table 1 Molecular weight distribution parameters of poly(4-PHMP)

Molecular weight distribution parameters

\begin{tabular}{|c|c|c|c|c|c|c|c|c|c|c|c|}
\hline \multirow[b]{2}{*}{ Compounds } & \multicolumn{3}{|c|}{ Total } & \multicolumn{4}{|c|}{ Fraction I } & \multicolumn{4}{|c|}{ Fraction II } \\
\hline & $M n$ & $M w$ & PDI & $M n$ & $M w$ & PDI & $\%$ & $M n$ & $M w$ & PDI & $\%$ \\
\hline Poly(4-PHMP) & 17717 & 22065 & 1.25 & 39400 & 48200 & 1.22 & 43 & 1360 & 2350 & 1.72 & 57 \\
\hline Poly(4-PHMP) & 9388 & 12508 & 1.33 & 19300 & 24800 & 1.28 & 44 & 1600 & 2850 & 1.78 & 56 \\
\hline
\end{tabular}

Abbreviations: Mn, number average molecular weight; Mw, weight average molecular weight; PDI, polydispersity index; 4-PHMP, 4-((2-phenylhydrazono)methyl)phenol.

${ }^{a} \mathrm{NaOCl}$ oxidant.

${ }^{\mathrm{b}} \mathrm{O}_{2}$ oxidant (despite of similar reaction conditions).

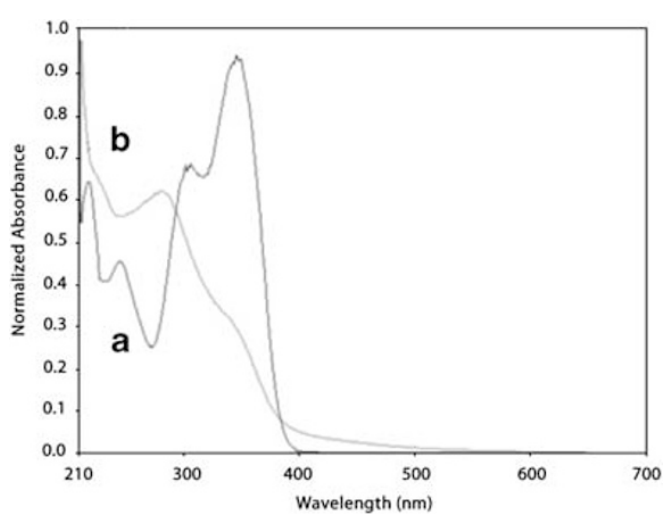

Figure 5 UV-vis spectra of 4-PHMP (a) and poly(4-PHMP) (b). A full color version of this figure is available at Polymer Journal online.

In previous papers describing the oxidative polycondensation of phenol and substituted phenols, NMR and FTIR analyses showed that the resulting polyphenols had a structure consisting of a mixture of phenylene and oxyphenylene units. ${ }^{4,14}$ Here, the structures of synthesized compounds were analyzed by ${ }^{1} \mathrm{H}-\mathrm{NMR}$ and FTIR spectroscopy. In comparing the IR spectrum of poly(4-PHMP) and 4-PHMP, the only difference that was observed was in the reduction of band strength and peak numbers from the IR spectrum of 4-PHMP (Figure 6). The peak at $1595 \mathrm{~cm}^{-1}$ was assigned to the characteristic absorption of $\mathrm{C}=\mathrm{N}$ vibration. In the IR spectrum of poly(4-PHMP), a broad peak centered at $3300 \mathrm{~cm}^{-1}$ was due to the vibration of the $\mathrm{O}-\mathrm{H}$ linkage of the phenolic group; peaks at 1234 and $1167 \mathrm{~cm}^{-1}$ were ascribed to the asymmetric vibrations of the $\mathrm{C}-\mathrm{O}-\mathrm{C}$ linkage and to the $\mathrm{C}-\mathrm{OH}$ vibration, and a peak at $1105 \mathrm{~cm}^{-1}$ was due to the symmetric vibration of the ether bond. The small peak at $1677 \mathrm{~cm}^{-1}$ was attributed to the carbonyl $(\mathrm{C}=\mathrm{O})$ stretching vibration, which may be formed by oxidation of the imine groups within the polymer pendent groups. ${ }^{8,11}$ These data showed that the polymer obtained from 4-PHMP was also composed of a mixture of phenylene and oxyphenylene units.

To identify the structures of the monomer and polymer, the ${ }^{1} \mathrm{H}-\mathrm{NMR}$ spectra were recorded in DMSO (Figure 7). The ${ }^{1} \mathrm{H}-\mathrm{NMR}$ spectrum of the polymer showed three peaks: a peak at $\delta 10.18$ p.p.m. due to the imine proton, a broad peak centered at $\delta 9.93$ p.p.m. due the phenolic group proton and a multiplet peak at $\delta 6.35-7.97$ p.p.m. ascribed to the aromatic protons and secondary amine proton.

The unit ratio was determined via acetylation of the polymer with acetic anhydride in the presence of excess pyridine at room temperature for $24 \mathrm{~h} .{ }^{1} \mathrm{H}-\mathrm{NMR}$ analysis of the product confirmed complete acetylation. Two peaks were observed in the ${ }^{1} \mathrm{H}-\mathrm{NMR}$

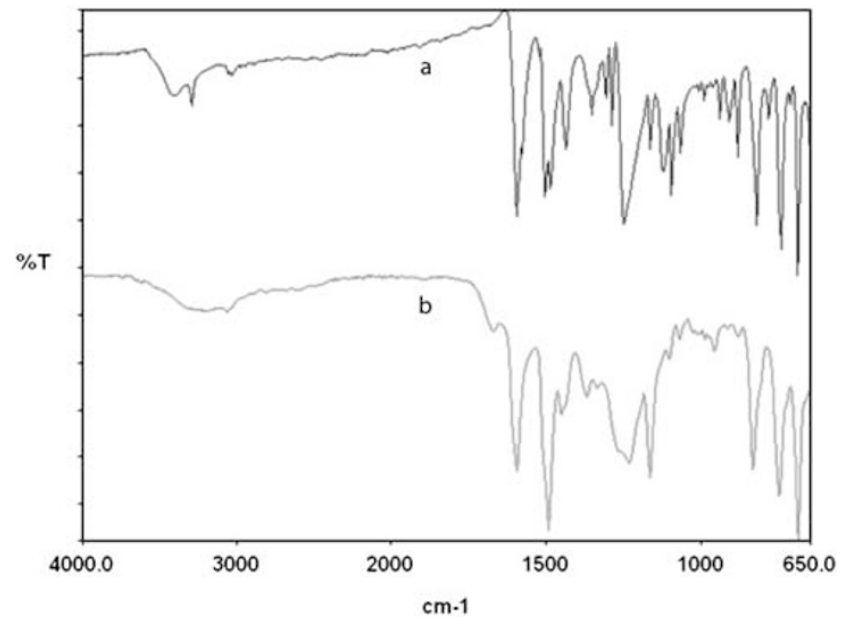

Figure 6 FTIR spectra of 4-PHMP (a) and poly(4-PHMP) (b). A full color version of this figure is available at Polymer Journal online.
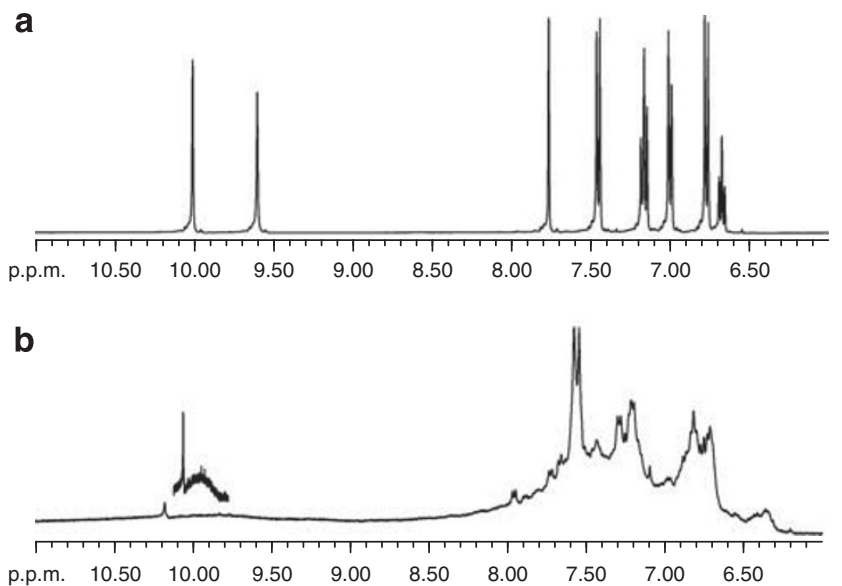

Figure 7 1H-NMR spectra of 4-PHMP (a) and poly(4-PHMP) (b).

spectrum; a broad peak centered at $\delta 7.4$ due to the polymer protons and a broad peak at $\delta 2.17-2.31$ assigned to the methyl protons of the acetyl group. The existence of a broad acetyl peak suggested that the polyphenol had at least two structurally different units. The unit ratio was calculated from the ratio of the integrated areas of the peaks for the acetyl and the polymer protons (see Supplementary information). According to this explanation, the percent ratio of phenylene and oxyphenylene units was calculated to be $63: 37$. 
a

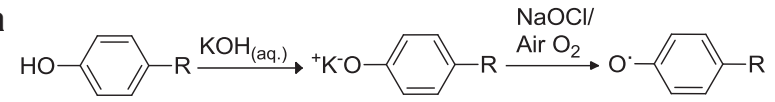

$\mathrm{R}:-\mathrm{HC}=\mathrm{N}-\mathrm{NH}-\mathrm{Ph}$

(I)

b

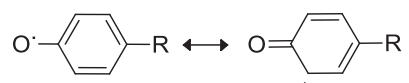

(I)

(II)

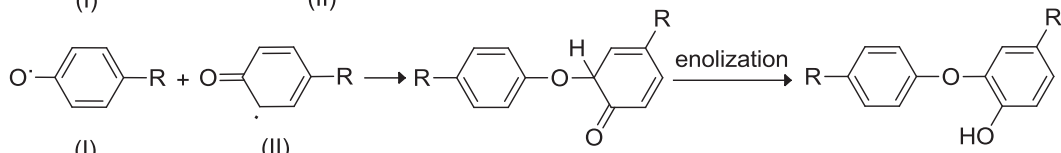

(l)

(II)

$\mathrm{HO}$

C<smiles>[R]c1ccc(Oc2cc([R])ccc2O)cc1</smiles>

Scheme 2 Proposed mechanism for the formation of poly(4-PHMP).
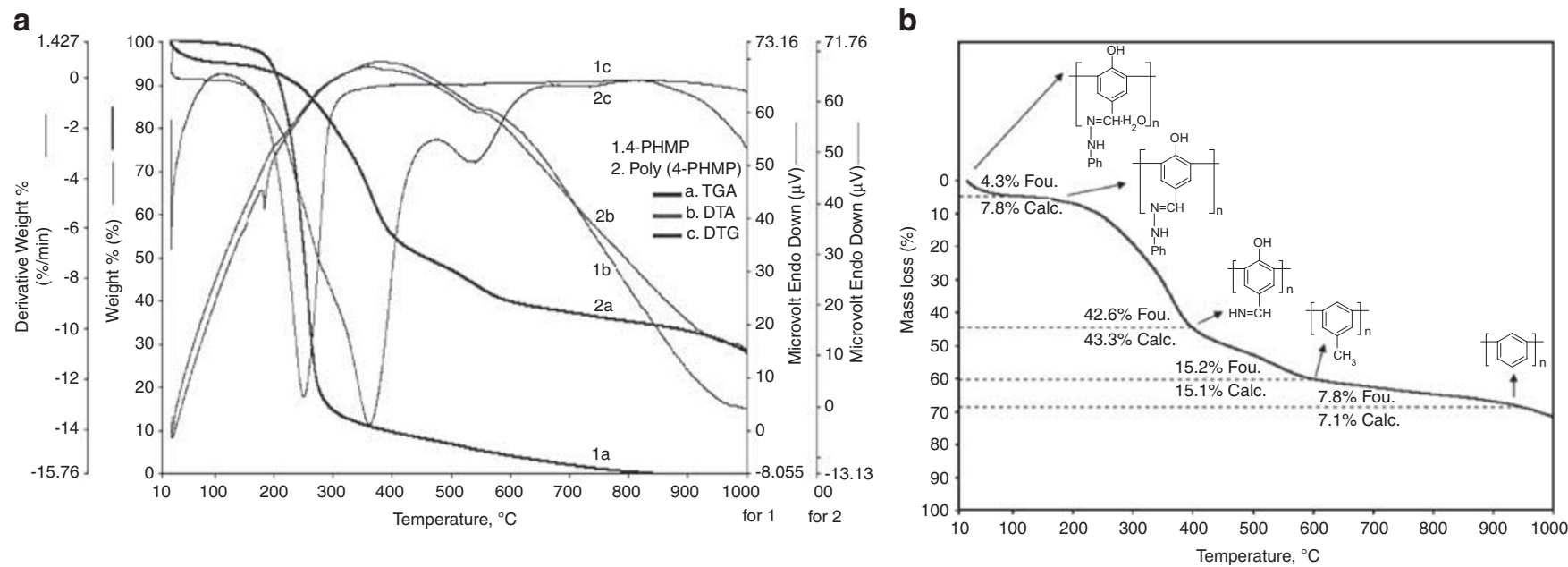

Figure 8 Thermo gravimetry-DTG-differential thermal analysis curves of the monomer and polymer (a) and decomposition pattern of poly(4-PHMP) (b). A full color version of this figure is available at Polymer Journal online.

According to the size exclusion chromatography analysis, the calculated number average molecular weight, weight average molecular weight and polydispersity index values of the polymer are given in Table 1. As seen in Table 1, two fractions for the polymer were obtained. According to the total values, the synthesized polyphenols had high-molecular weights, indicating nearly 100 repeated units. These results confirmed that a polymeric structure was obtained. These results showed that poly(4-PHMP) had higher number average molecular weight and weight average molecular weight values than the NO-type polyphenols, such as O-2-MPIMP ${ }^{15}$ and O-4-TMAP. ${ }^{16}$

These studies investigating the polymer structure and kinetics of the process, taken together with data from the literature ${ }^{17,18}$ suggest the following mechanism of 4-PHMP oxidative polycondensation in an alkaline medium: Scheme $2 \mathrm{a}$.

The resonance forms of the intermediate radicals undergo recombination followed by the enolization of dimers: Scheme $2 \mathrm{~b}$.

The recombination of two radicals II yields the following structures: Scheme 2c.
The dimers, trimers and multimer are likewise oxidized. The process-limiting step is the electron transfer from the monomer anion to the oxidant.

Analytical data of the compounds were presented in the Experimental procedures. The results from elemental analyses of the two compounds were in agreement with the theoretical calculations. The analytical and spectroscopic data enabled us to predict the possible structures of the compounds, as shown in Figures 5-7. On the basis of the elemental analyses and spectroscopic characterization, these compounds were presumed to have the structures shown in Scheme 1.

\section{Thermal properties of 4-PHMP and poly(4-PHMP)}

Thermogravimetric, derivative thermogravimetric and differential thermal analysis (thermo gravimetry-differential thermogravimetry) curves of the monomer and polymer are shown in Figure 8a, and the likely polymer degradation steps are presented in Figure $8 \mathrm{~b}$.

The initial decomposition temperature of 4-PHMP was higher than that of poly(4-PHMP) due to loss of water of crystallization. ${ }^{19}$ The 
presence of water can be seen in the TGA curves of poly(4-PHMP) (Figures 8a and b). Although the initial degradation temperature of poly(4-PHMP) was lower than that of 4-PHMP, the polymer had more carbine residue and $50 \%$ degradation temperature, which was $249^{\circ} \mathrm{C}$ for 4 -PHMP, was $459^{\circ} \mathrm{C}$ for poly(4-PHMP). According to Figure 8b, poly(4-PHMP) exhibited three-stage decomposition after the loss of one water molecule in the temperature range of $20-120{ }^{\circ} \mathrm{C}(4.3 \%$ mass loss observed, compared with $7.8 \%$ mass loss calculated). The first stage of decomposition started at $120^{\circ} \mathrm{C}$ and involved a $42.6 \%$ mass loss (compared with $43.3 \%$ calculated mass loss), which corresponded to loss of the aniline group. In the second stage, decomposition started at $396^{\circ} \mathrm{C}$, with a mass loss of $15.2 \%$ (compared with a calculated mass loss of $15.1 \%$ ), which may be due to the removal of one amine group $(-\mathrm{NH})$ and one $-\mathrm{OH}$ group attached to the phenyl ring. The third stage of decomposition started at $590{ }^{\circ} \mathrm{C}$ and involved a $7.8 \%$ mass loss (compared with a $7.1 \%$ calculated mass loss), which may be due to the removal of one methyl group $\left(-\mathrm{CH}_{3}\right)$ attached to the aromatic benzene ring. Although the complete decomposition of the monomer occured at $880^{\circ} \mathrm{C}$, the total weight loss of the polymer was $72.2 \%$ at $1000{ }^{\circ} \mathrm{C}$. In addition, in the differential thermal analysis curve of the monomer, an endothermic peak was observed at $183^{\circ} \mathrm{C}$.

\section{Optical properties}

The absorption edges of the poly(4-PHMP) shifted to higher wavelengths than those of 4-PHMP as a result of increasing conjugation. As expected, the polymer had a lower optical band gap than the monomer. Optical band gap $\left(E_{g}\right)$ values calculated from absorption edges ${ }^{20}$ for 4-PHMP and poly(4-PHMP) were 3.26 and $3.11 \mathrm{eV}$, respectively (Figure 5).

\section{Electrochemical properties}

Figure 9a shows cyclic voltammograms of 4-PHMP and poly(4PHMP). Highest occupied molecular orbital-lowest unoccupied molecular orbital energy levels and the electrochemical band gaps $\left(E_{g}{ }^{\prime}\right)$ were estimated using the oxidation onset $\left(E_{\mathrm{ox}}\right)$ and reduction onset $\left(E_{\text {red }}\right)$ values, ${ }^{21}$ as shown below.

$$
\begin{aligned}
& E_{\mathrm{HOMO}}=-\left(4.39+E_{\mathrm{ox}}\right) \\
& E_{\mathrm{LUMO}}=-\left(4.39+E_{\mathrm{red}}\right) \\
& E_{g}^{\prime}=E_{\mathrm{LUMO}}-E_{\mathrm{HOMO}}
\end{aligned}
$$

4-PHMP and poly(4-PHMP) were electrochemically active in the oxidation and reduction regions. The electrochemical data of 4-PHMP and poly(4-PHMP) were listed in Table 2 and Figure 9b.

As seen in Figure 9 and Table 2, poly(4-PHMP) had a lower band gap than its monomer because of the polyconjugated structures of the polymers, which increased highest occupied molecular orbital and decreased lowest unoccupied molecular orbital energy levels resulting in lower band gaps (Figure 9b). The $E_{g}^{\prime}$ value measured for poly(4PHMP) was rather low when compared with that of other NO-type Schiff-base polyphenols. The lowest band gap $(1.95 \mathrm{eV})$ was observed among synthesized compounds in literature. ${ }^{22}$ The results obtained in this study are compatible with the literature values. It is well known that lower band gaps facilitate electronic transitions between highest occupied molecular orbital and lowest unoccupied molecular orbital energy levels and make the polymers more electroconductive than their monomers.
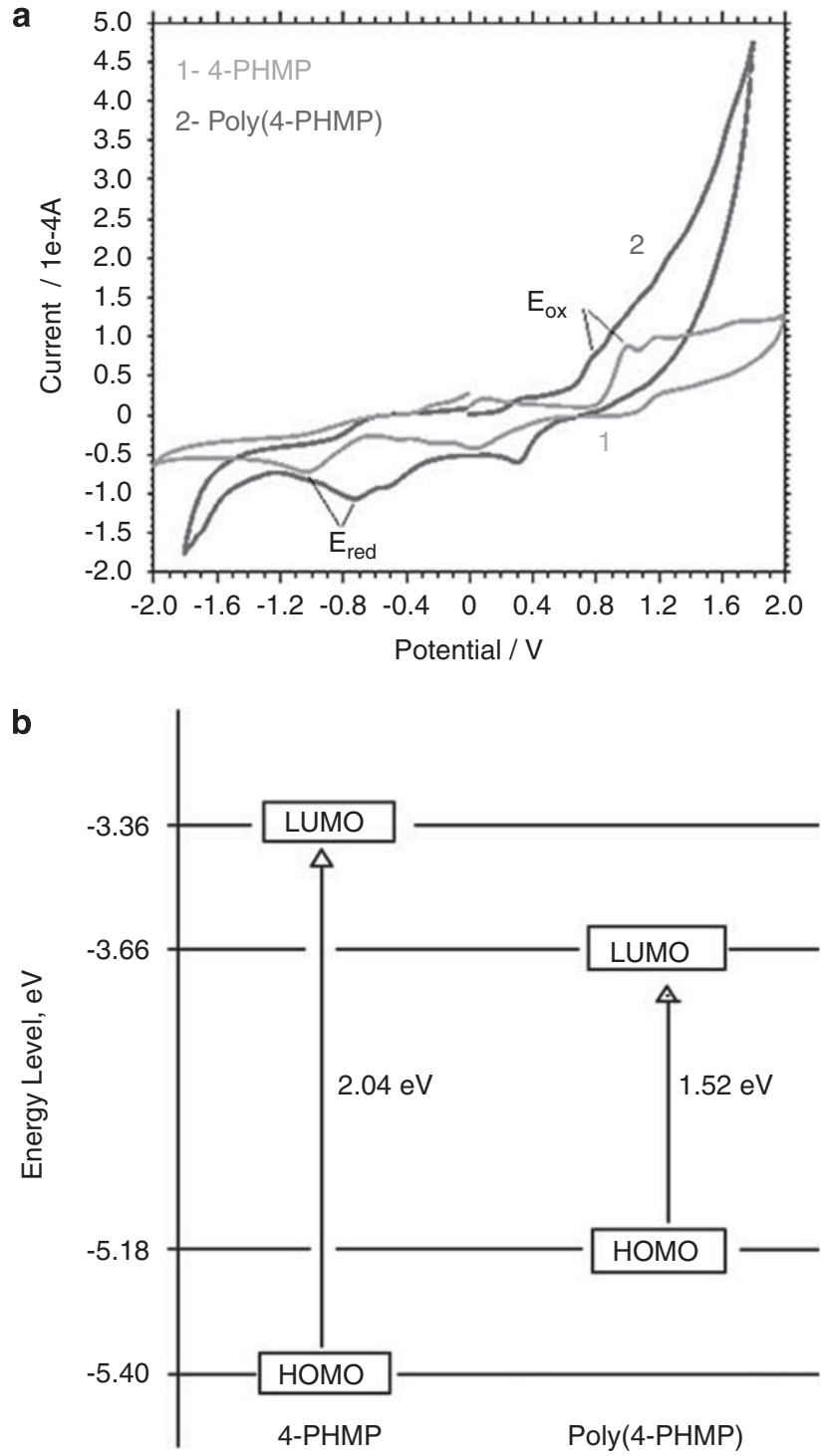

Figure 9 (a) Cyclic voltammograms of 4-PHMP and poly(4-PHMP) (b) highest occupied molecular orbital-lowest unoccupied molecular orbital energy levels and electrochemical band gaps of the synthesized compounds. A full color version of this figure is available at Polymer Journal online.

Table 2 Electrochemical data for the monomer and its polymer

\begin{tabular}{lccccc}
\hline Compounds & $\mathrm{E}_{\text {ox }}(\mathrm{V})$ & $\mathrm{E}_{\text {red }}(\mathrm{V})$ & HOMO $(\mathrm{eV})$ & LUMO $(\mathrm{eV})$ & $\mathrm{E}_{\mathrm{g}}{ }^{\prime}(\mathrm{eV})$ \\
\hline 4-PHMP & 1.010 & -1.028 & -5.40 & -3.36 & 2.04 \\
Poly(4-PHMP) & 0.785 & -0.728 & -5.18 & -3.66 & 1.52
\end{tabular}

Abbreviations: HOMO, highest occupied molecular orbital; LUMO, lowest unoccupied molecular orbital; 4-PHMP, 4-((2-phenylhydrazono)methyl)phenol.

\section{CONCLUSIONS}

In this study, a new type of polymer with low band gap characteristics, poly(4-PHMP), was synthesized. To examine their influence on the polymerization reaction, several parameters including reaction temperature, time and initial concentrations of alkaline medium and oxidant were altered, and the parameters were found to have great effects the polymer yield. Poly(4-PHMP) with reactive imine and 
hydroxy groups was readily soluble in highly polar organic solvents such as methanol, DMSO and dimethylformamide. Thermal analysis showed that poly(4-PHMP) had relatively high thermal stability. The observed band gaps were sufficiently low to make the polymer highly promising for photovoltaic applications, and other interesting properties made poly(4-PHMP) suitable for applications in various other fields such as graphite materials.

\section{ACKNOWLEDGEMENTS}

I express my sincere gratitude to Dr S Karabuga and M Ozhallac for their helpful discussions.

1 Kim, D. H., Cho, H. I., Zyung, T., Do, L. M., Bark, K. M., Shin, G. C. \& Shin, S. C. New tetradentate Schiff-base polymers: preparation of poly[2,5-(didodecyloxy)phenylene1,4-diyl-alt- $\mathrm{N}, \mathrm{N}^{\prime}$-(o-phenylene)-bis(salicylideneiminato-4,4'-diyl)] and poly[2,5-(didodecyloxy)phenylene-1,4-diyl-alt- $\mathrm{N}, \mathrm{N}^{\prime}$-(alkylidene)-bis(salicylideneiminato-4,4'-diyl)]s. Eur. Polym. J. 38, 133-137 (2002).

2 Liu, W., Bian, S. P., Li, L., Samuelson, L., Kumar, J. \& Tripathy, S. Enzymatic synthesis of photoactive poly(4-phenylazophenol). Chem. Mater. 12, 1577-1584 (2000).

3 Skotheim, T. A. \& Reynolds, J. R. Handbook of Conducting Polymers, Third edn. (CRC Press Taylor \& Francis Group, Broken Sound Parkway NW., 2006).

4 Akkara, J. A., Senecal, K. J. \& Kaplan, D. L. Synthesis and characterization of polymers produced by horseradish-peroxidase in dioxane. J. Polym. Sci. Part a-Polym. Chem. 29, 1561-1574 (1991).

5 Kobayashi, S., Kim, Y. J. \& Uyama, H. Peroxidase-catalyzed oxidative polymerization of phenol with a nonionic polymer surfactant template in water. Macromol. Biosci. 4, 497-502 (2004).

6 Mart, H. Oxidative polycondensation reaction. Des. Monomer. Polym. 9, 551-588 (2006).

7 Ragimov, A. V., Mamedov, B. A. \& Gasanova, S. G. New efficient dielectric and antistatic materials based on oligoaminophenols. Polym. Int. 43, 343-346 (1997).

8 Kaya, L., Demir, H. O. \& Vilayetoglu, A. R. The synthesis and characterisation of planar oligophenol with schiff base substitute. Synthetic Met. 126, 183-191 (2002).
9 Kaya, I. Synthesis, characterization, conductivity, band gap, and thermal analysis of poly-[(2-mercaptophenyl)iminomethyl]-2-naphthol and its polymer-metal complexes. J. Inorg. Organomet. Polym. Mater. 20, 369-379 (2010).

10 Mart, H. Oligo-ortho-chloroazomethinephenol and its metal complexes: Synthesis, characterization, antimicrobial and thermal properties. J. Macromol. Sci. Pure Appl. Chem. A42, 1197-1206 (2005).

11 Kaya, I., Vilayetoglu, A. R. \& Topak, H. Synthesis of oligo-ortho-azomethinephenol and its oligomer-metal complexes: characterization and application as anti-microbial agents. J. Appl. Polym. Sci. 85, 2004-2013 (2002).

12 Demir, H. O. Ketimine substituted polyphenol: synthesis, characterizations and investigation of thermal and electrochemical properties. J. Appl. Polym. Sci. (2012) (Accepted).

13 Furniss, B. S., Hannaford, A. J., Smith, P. W. G. \& Tatchell, A. R. Vogel's Textbook Practical Organic Chemistry. Chapter 6 (Wiley, New York, 1989).

14 Kaya, I. \& Bilici, A. Synthesis, characterization, thermal stability, conductivity and band gap of oligo-4-[(2-hydroxybenzylidene)amino]benzoic acid. Synthetic Met. 156, 736-744 (2006).

15 Kaya, I. \& Koca, S. Synthesis, characterization, thermal properties and conductivity of oligo-4-[(2-methoxyphenylimino)methyl]phenol. Iran. Polym. J. 18, 25-35 (2009).

16 Kaya, I. \& Aydin, A. Synthesis, characterization, thermal stability, conductivity and band gaps of monomer and oligo-4-[(thien-2-yl-methylene)amino] phenol. E-Polym. 071, 1-14 (2008)

17 Strigun, L. M., Vartanyan, L. S. \& Emanuel, N. M. Oxidation of sterically hindered phenols. Russ. Chem. Rev. 37, 421-434 (1968).

18 Kaya, I. \& Koyuncu, S. The synthesis and characterization of oligo-N-4-aminopyridine, oligo-2-[(pyridine-4-yl-imino) methyl] phenol and its some oligomer-metal complexes. Polymer 44, 7299-7309 (2003).

19 Cazacu, M., Marcu, M., Vlad, A., Rusu, G. I. \& Avadanei, M. Chelate polymers. VI. New copolymers of the some siloxane containing bis(2,4-dihydroxybenzaldehydimine)Me2 + with bis(p-carboxyphenyl)diphenylsilane. J. Organomet. Chem. 689, 3005-3011 (2004).

20 Colladet, K., Nicolas, M., Goris, L., Lutsen, L. \& Vanderzande, D. Low-band gap polymers for photovoltaic applications. Thin Solid Films 451, 7-11 (2004).

21 Cervini, R., Li, X. C., Spencer, G. W. C., Holmes, A. B., Moratti, S. C. \& Friend, R. H. Electrochemical and optical studies of PPV derivatives and poly(aromatic oxadiazoles). Synthetic Met. 84, 359-360 (1997).

22 Kaya, I. \& Yildirim, M. Synthesis, characterization, thermal stability, conductivity, and band gap of a new aromatic polyether containing an azomethine as a side. J. Appl. Polym. Sci. 106, 2282-2289 (2007).

Supplementary Information accompanies the paper on Polymer Journal website (http://www.nature.com/pj) 